\title{
The Revival of Old Hydraulic Turbines for Innovative Hydropower Generation: Water Wheels, Archimedes Screws, Deriaz and Girard Turbines
}

\author{
Emanuele Quaranta* \\ Joint Research Centre of European Commission, Ispra, Italy
}

*Corresponding author: Emanuele Quaranta, Joint Research Centre of European Commission, Ispra, Italy, Email: emanuele.quaranta@ec.europa.eu / quarantaemanuele@yahoo.it
Received Date: May 18, 2020

Published Date: June 09, 2020

\begin{abstract}
Hydropower is the most developed renewable energy technology. It has evolved over hundreds of years, with the highest growth in the Twentieth century. Some technologies are continuously improving, while others have been forgotten. Four emerging hydropower turbines developed in the past, but forgotten in the last century, are here presented: water wheels, Archimedes screws, Deriaz, and Girard turbines. Their revival is related to the new needs that hydropower must face. The Updraft free-exit-flow turbine, not yet a commercial product, is also described.
\end{abstract}

Keywords: Archimedes; Deriaz; Girard; hydropower; hydro turbine; water wheel

\section{Introduction}

Hydropower represents the largest share of renewable electricity generation, with slightly more than $1200 \mathrm{GW}$ of installed capacity, where $328 \mathrm{GW}$ are run-off-river. Hydropower is a renewable energy source, with benefits on flood control, water management, promotion of leisure activities and stabilization of the electric grid [1]. It steadily evolved since the first century BC, when the water wheel was introduced. Hydropower underwent its major technological development from the end of the Nineteenth century, with the development of big hydro plants. Pelton, Francis and Kaplan turbines were introduced, replacing both the previous turbines, like the Girard turbine, and the small/low head hydro plants that used water wheels [2]. Nowadays, hydropower has to deal with new energetic and environmental challenges, e.g.: the need of more flexible turbines to face the instabilities of the electric grid and the variable flow rates, fish friendly turbines [3] and low head turbines [4]. Therefore, new emerging hydropower technologies are under development [1], while some old hydro technologies are again under consideration, in particular: water wheels, Archimedes screws, Deriaz turbines and Girard turbines. Their operating conditions are shown in Figure1. The updraft free-exit-flow is also described, due to its key innovations, although it has not yet reached the commercial stage. Figure 2 shows the analysed turbines. 

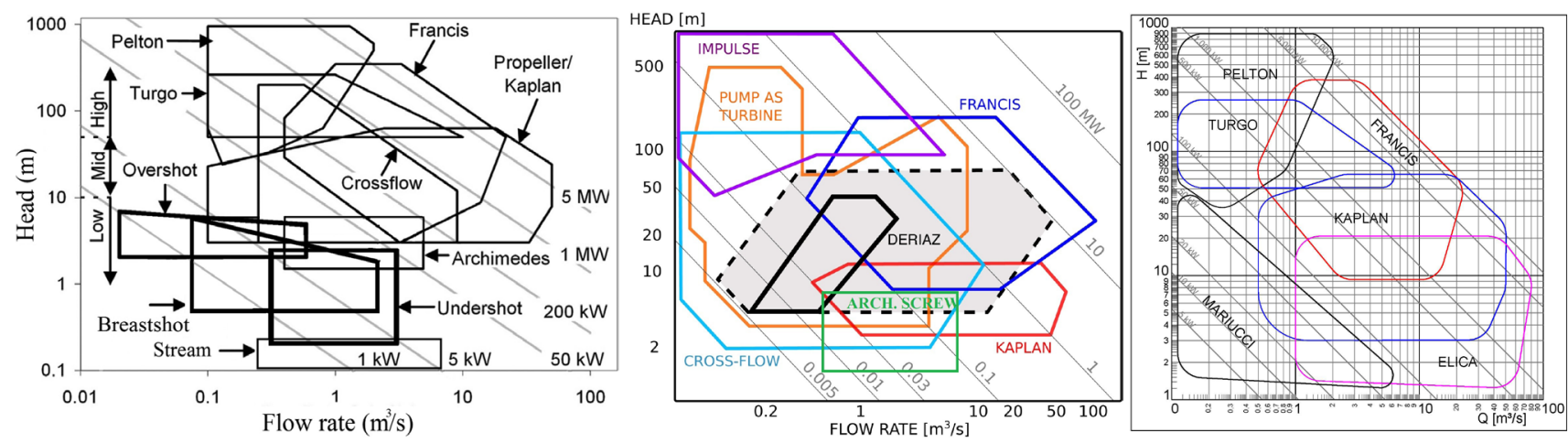

Figure 1: Range of operation of the discussed turbines, adapted from Quaranta and Revelli (2018), Morabito et al. (2019) and Pers. Comm. of Teti s.r.l. Head on Y-axis, flow rate on X-axis.
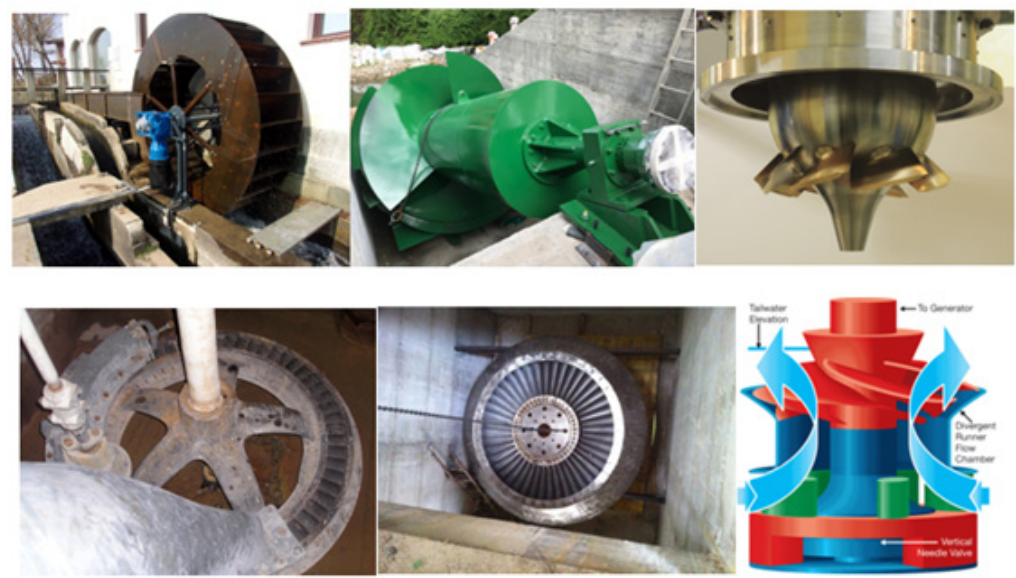

Figure 2: Starting from top left to bottom right. Breastshot water wheel (Gatta s.r.l.), Hydrodynamic screw (Artingegneria), Deriaz turbine (Mhylab), Girard turbine (Industrie Ensemble), Mariucci turbine (Teti s.r.l.), Uplift turbine (Kao, 1985).

\section{Vertical Water Wheels and Archimedes Screws as Low Head Hydropower Converters}

Nowadays, due to the large amount of low head hydropower potential in irrigation canals and at old mill sites, gravity machines (i.e. that mainly exploit the water weight to rotate) are emerging as cost effective low head hydropower converters. Gravity machines, like gravity vertical water wheels (GVWW) and Archimedes screws (AS), used in the past to power water mills and to pump water, are the most diffuse machines in this context. The advantages of gravity machines with respect to reaction turbines are the low costs while maintaining good hydraulic efficiency, more fish friendly behavior and exploitation of very low heads (0-6 m). However, the slow rotational speed requires the use of a gearbox [4]. Even before the eve of hydroelectricity (in the XIX century), GVWW had already allowed the early development of large industrial sites (metallurgy, paper, and textile industries) in Europe and in the USA [5]. Using steel and optimized blades, Poncelet in 1825, Sagebien in 1858, Zuppinger in 1883 , achieved optimized design of the GVWW allowing to reach high efficiency [6]. GVWW were almost forgotten during the Twentieth century due to the development of new turbines for large hydro plants, re-emerging nowadays. GVWWs have a horizontal rota- tion axis, with a series of blades around the external circumference. GVWWs are used in sites with existing head differences, differently from stream water wheels (floating water wheels) used in zero head sites. The most seminar review papers on water wheels are: Muller \& Kauppert [6], Quaranta \& Revelli [7] and Quaranta [8]. Depending on the inflow, GVWWs can be classified into:

1. undershot water wheels, for heads below $1.5 \mathrm{~m}$ and maximum flow rates below $1 \mathrm{~m}^{3} / \mathrm{s}$ per metre width;

2. breastshot water wheels, for heads below $4 \mathrm{~m}$ and maximum flow rates below $0.6-0.8 \mathrm{~m}^{3} / \mathrm{s} \cdot \mathrm{m}$;

3. overshot water wheels, for heads from $3 \mathrm{~m}$ to $6 \mathrm{~m}$ and maximum flow rates below $0.2 \mathrm{~m}^{3} / \mathrm{s} \cdot \mathrm{m}$.

Maximum hydraulic efficiencies of GVWW range from $75 \%$ to $85 \%$, while stream water wheels exhibit maximum power coefficient (ratio of power output to input kinetic power) of 0.4 , that can be increased to 0.6 using shrouds and floats. In Quaranta and Revelli [7] a GVWW database was compiled. Archimedes screws (AS) are gravity machines composed of 3-5 (3 is the typical number) helical blades wrapped around their rotation axis, that is inclined on the horizontal with an angle between $25^{\circ}$ and $35^{\circ}$. The most seminal 
review papers and works are Water \& Aggidis [9] and Lubitz et al. [10]. One theory regarding its creation tells that the King of Egypt asked Archimedes to find a way to remove water from his ships, while another suggests that As was created hundreds of years before Archimedes birth, and he just adapted it to make it popular. After Archimedes, Vitruvius wrote about the screw pump during the first century BC. The AS was used extensively in the Netherlands to create polders (reclaimed land that is under sea level), and to pump water. Nowadays, there are numerous companies that sell ASs as hydropower turbines, for head differences typically below 6 $\mathrm{m}$ and flow rates up to $8 \mathrm{~m}^{3} / \mathrm{s}$ for a $4 \mathrm{~m}$ screw diameter. Maximum hydraulic efficiencies can be identified between 75 and $85 \%$, as a function of the screw inclination. When the bottom shroud is fixed and does not rotate with the screw, this machine is called Hydrodynamic screw.

\section{The Deriaz Turbine as Flexible Turbine and Pump- as-Turbine}

The Deriaz turbomachine (DT), presented by engineer Paul Deriaz, was the first diagonal flow pump-turbine to be designed, in 1926. It has a vertical axis, and adjustable runner blades. The most recent review on the Deriaz turbine is presented in Morabito [17]. The DT has a lower specific speed than a Kaplan turbine, and it works more efficiently at partial loads and at higher available head than a Kaplan turbine, like Francis turbines. Furthermore, the reduction of specific speed leads to a reduction in the radial extension at the leading edge of the runner. However, differently from Francis turbines, DTs have adjustable runner blades (DT was at first ambiguously called "Francis at variable pitch"). The importance of the Deriaz turbine can be seen in the higher flexibility at variable flow rates, thus an elevated efficiency at low guide vane openings. The maximum efficiency of DTs is around 90\%, that can be kept constant from $30 \%$ to $120 \%$ of the design flow rate. Nowadays, the need of a more flexible turbine operation and pumped hydropower plants, makes the DT an emerging technology in this context, being able to work in pumping mode. However, the hydraulic conditions require more blades than a Kaplan turbine, with an increase in the ratio of blade length to spacing, which makes the placement of the large pivot bearings very difficult. In Quaranta and Hendrick (2020) a database of existing DTs was compiled.

\section{The Mariucci Turbine as Evolution of the Girard Turbine}

The Girard turbine is an axial flow action turbine. No scientific paper speaks exclusively about its performance, except few reports $[11,12]$. By 1850-1880, the existing Fourneyron (now not used anymore) and Francis turbines did not allow to deal with heads higher than $120 \mathrm{~m}$, while there was a big demand for turbines to use smaller mountain flows with higher heads, especially in the Alpin regions. The action turbines appeared to be the key technology in this context, but their major problem was the rapid erosion of the runner and high flow velocity. In light of this, Louis-Dominique Girard designed in 1854 an action turbine, with axial flow, with a hor- izontal axis and a controlled water jet to the rotor blades. Its efficiency was probably about $60 \%$. This turbine became the reference turbine in the French Alps during 1860-1880, as a consequence of the paper industry development. Between 1869 and 1882, Aristide Bergès used a turbine derived from the Girard one to exploit a head of $480 \mathrm{~m}$, encountering difficulties due to cavitation erosion [2]. The Girard turbine has been forgotten until 2017, when an Italian engineer developed the Mariucci turbine, an optimized Girard turbine with vertical axis with the possibility of adjusting the vertical position, as a function of the downstream water level; nozzle friction and leakages are minimized. The Mariucci turbine can work for heads below $3 \mathrm{~m}$, and can exploit flow rates up to $6 \mathrm{~m}^{3} / \mathrm{s}$ (being an axial turbine), while Pelton and Turgo turbines would be able to exploit few liters per second in such low head sites. The efficiency is between $85 \%$ and $90 \%$ from $30 \%$ of the design flow rate. At the moment, the owner society Teti s.r.l. has installed four turbines from $2 \mathrm{~kW}$ to $80 \mathrm{~kW}$ [13].

\section{The Updraft Free-Exit-Flow Turbine}

The Updraft free-exit-flow turbine was introduced by Kao [14]. The turbine was designed with a vertical-shaft, and the water that flows through the runner in an upward direction. The major components are the spiral case, stay vanes, a needle valve, a divergent runner chamber, a runner, and a transmission shaft. Except the transmission shaft, all other turbine components are submerged or partially submerged in the tailrace water. By directing the water to flow upward, the hydraulic thrust, which is approximately equal to the hydrostatic pressure times the horizontal projection of the runner, acts in the opposite direction of the gravitational field. In this way, the weight of the runner-generator unit is partially supported by the upward pressure force. Thus, the dynamic stress on the thrust bearing and the transmission shaft and the load on the powerhouse support structure are substantially reduced. The second innovation is the free open-exit-flow discharge arrangement, where the water leaves the turbine as a free water flush. As the flush plunges into the tailrace, it improves the natural aeration process, air entrainment, and turbulent mixing, increasing the dissolved oxygen. By using the free open-exit-flow discharge arrangement, the need of a draft tube for partial recovery of the kinetic energy is reduced. The third innovation of the new turbine system is the adoption of a vertical needle valve instead of wicket gates to control the flow. The last innovation allows the flow passage prior to the runner chamber to be more open and streamlined, making the new turbine more fish friendly. However, the maximum efficiencies are below 70\% [14,15].

\section{Conclusion}

The hydropower sector is continuously in evolution, in order to cope with new needs, like the required higher flexibility, and the more variable and difficult operating conditions. Emerging technologies are under development, while some forgotten ones are undergoing a revival. Water wheels and Archimedes screws can be employed in very low head sites, while the Deriaz turbine can be also used for pumping, with a variable flow rate. The Mariucci 
turbine, an evolution of the Girard turbine, may conceptually work in the same range of a Francis turbine, although, being at its initial stage, it has been employed for power output like micro Kaplan and Francis turbines [18] below $80 \mathrm{~kW}$. The Updraft free-exit-flow turbine, although it's several advantages, has not been widely used, probably due to its low efficiency.

\section{Acknowledgement}

Thanks to Pierre-Louise Viollet (Honorary scientific president of Société Hydrotechnique de France, and Honorary Professor at Ecole des Ponts Paristech) for his comments on the paper.

\section{Conflict of Interest}

No conflict of interest.

\section{References}

1. Kougias I, George A, François A, Sabri D, Urban L, et al. (2019) Analysis of emerging technologies in the hydropower sector. Ren Sust Energy Rev 113: 109257

2. Viollet PL (2017) From the water wheel to turbines and hydroelectricity. Technological evolution and revolutions. Comptes Rendus Mécanique 345(8): 570-580

3. Hogan T, Cada G, Amaral S (2014) The Status of Environmentally Enhanced Hydropower Turbines, Fisheries 39 (4): 164-172.

4. Bozhinova S, Kisliakov D, Müller G, Hecht V, Schneider S (2013) Hydropower converters with head differences below $2.5 \mathrm{~m}$. Proc ICEEnergy 166(3):107-119.

5. Viollet PL (2005) Histoire de l'Energie Hydraulique, Presses des Ponts et Chaussées (ISBN 2-85978-4144).

6. Müller G, Kauppert K (2004) Performance characteristics of water wheels. J Hydraul Res 42(5): 451-460.
7. Quaranta E, R Revelli (2018) Gravity water wheels as a micro hydropower energy source: A review based on historic data, design methods, efficiencies and modern optimizations. Ren Sust Energy Rev 97: 414-427.

8. Quaranta E (2018) Stream water wheels as renewable energy supply in flowing water: Theoretical considerations, performance assessment and design recommendation. Energy Sust Dev 45: 96-109.

9. Waters S, Aggidis G (2015) Over 2000 years in review: revival of the Archimedes screw pump to turbine. Renew Sust Energy Rev 51: 497505 .

10. Lubitz D, Lyons M, Simmons S (2014) Performance model of Archimedes screw hydro turbines with variable fill level. J Hydraul Eng 140 (10): 04014050 .

11. United States Commissioners (1891) Reports of the United States Commissioners to the Universal Exposition of 1889, Paris, Volume III, Washington: Government Printing Office.

12. Hosszuréty Z (1992) Turbine hydraulique Girard simplifiée pour faibles et très faibles puissances. La Houille Blanche, $\mathrm{N}^{\circ} 1$, pp. 79-83.

13. Quaranta E (2020) Hydropower innovations and sustainability: study case collection. Sustainability, in progress.

14. Kao DT (1985) New Hydroturbine Design for Improved Water Quality and Reduced Fish Mortality. Proceedings, Symposium on Small Hydropower and Fisheries, Aurora, Colorado, pp. 403 - 408.

15. Shijin Huang (2000) Analysis and design of a new updraft free-exitflow low-head hydropower turbine system. Retrospective Theses and Dissertations. Iowa State University.

16. Quaranta E, Hendrick P (2020) Rotational speed estimation of Deriaz turbines: trends and dataset collection, 6th IAHR Europe Congress.

17. Morabito, A., e Silva, G. D. O., \& Hendrick, P. (2019). Deriaz pump-turbine for pumped hydro energy storage and micro applications. Journal of Energy Storage, 24, 100788.

18. Quaranta, E. (2019). Optimal Rotational Speed of Kaplan and Francis Turbines with Focus on Low-Head Hydropower Applications and Dataset Collection. Journal of Hydraulic Engineering, 145(12), 04019043. 